\title{
Unstable Operation of Francis Pump-Turbine at Runaway: Rigid and Elastic Water Column Oscillation Modes
}

\author{
Christophe Nicolet ${ }^{1}$, Sébastien Alligné ${ }^{2}$, Basile Kawkabani ${ }^{3}$, \\ Jean-Jacques Simond ${ }^{3}$ and François Avellan ${ }^{2}$
}

\author{
${ }^{1}$ Power Vision Engineering sàrl, 1 ch. des Champs-Courbes, CH-1024 Ecublens, Switzerland, \\ christophe.nicolet@powervision-eng.ch \\ ${ }^{2}$ Laboratory for Hydraulic Machines, Ecole Polytechnique Fédérale de Lausanne, EPFL, CH-1015 Lausanne, \\ Switzerland, sebastien.alligne@epfl.ch, francois.avellan@epfl.ch \\ ${ }^{3}$ Laboratory of Electrical Machines, Ecole Polytechnique Fédérale de Lausanne, EPFL, CH-1015 Lausanne, \\ Switzerland, basile.kawkabani@epfl.ch, jean-jacques.simond@epfl.ch
}

\begin{abstract}
This paper presents a numerical simulation study of the transient behavior of a $2 \times 340 \mathrm{MW}$ pump-turbine power plant, where the results show an unstable behavior at runaway. First, the modeling of hydraulic components based on equivalent schemes is presented. Then, the 2 pump-turbine test case is presented. The transient behavior of the power plant is simulated for a case of emergency shutdown with servomotor failure on Unit 1 . Unstable operation at runaway with a period of 15 seconds is properly simulated using a 1-dimensional approach. The simulation results points out a switch after 200 seconds of the unstable behavior between a period of oscillations initially of 15 seconds to a period of oscillation of 2.16 seconds corresponding to the hydraulic circuit first natural period. The pressure fluctuations related to both the rigid and elastic water column mode are presented for oscillation mode characterization. This phenomenon is described as a switch between a rigid and an elastic water column oscillation mode. The influence of the rotating inertia on the switch phenomenon is investigated through a parametric study.
\end{abstract}

Keywords: Transient behavior, runaway, instabilities, oscillation modes.

\section{Introduction}

Abnormal operation of Francis pump-turbines at runaway resulting from guide vanes servomotor failure is standard case investigated during transient analysis [9], [2]. Due to the S-shape of pump-turbines characteristics in turbine mode [10], the operation at runaway usually leads to unstable behavior characterized by a large period of oscillations typically between 8 to 20 seconds, corresponding to the so called hydromechanical mode. The period of the hydromechanical mode depends on the rotating inertias, the penstock water inertia and on the local gradient of the turbine characteristic in the S-shape as it is well described by Martin [5], [6]. The analytical prediction of the period of the oscillations at runaway provided by Martin was validated by Dörfler et al. by measurements made during speed no load operation on the prototype of Francis pump-turbine [1]. However, during these tests, a lower period oscillation phenomenon was observed and described as the medium frequency unstable mode and it was noticed that the phenomenon was oscillating at a period close to the period of the first natural period of the piping system.

This paper presents a numerical simulation study of the transient behavior of a $2 \times 340 \mathrm{MW}$ pump-turbine power plant, where the results show an unstable behavior at runaway. First, the modeling of hydraulic components based on equivalent scheme representation is presented. Then, the test case is described. The emergency shutdown of the 2 units is simulated considering a servomotor failure on the Unit 1, while the guide vanes of the unit 2 are closed normally. Unstable operation of Unit 1 at runaway with a period of 15 seconds is properly simulated using the 1-dimensional approach. The simulation results points out a switch after 200 seconds of the unstable behavior between a period of oscillations initially of 15 seconds to a period of oscillation of 2.16 seconds corresponding to the hydraulic circuit first natural period. This phenomenon is described as a switch between a rigid and an elastic water column oscillation mode. The switch phenomenon is investigated by means of eigen values and eigen modes analysis of the entire hydraulic system including rotating inertias and also through time domain simulations. The role of the

Accepted for publication May 27 2009: Paper number O09032S

Corresponding author: Christophe Nicolet, Dr., christophe.nicolet@powervision-eng.ch

This manuscript was presented at the $24^{\text {th }}$ IAHR Symposium on Hydraulic Machinery and Systems, October 27-31, 2008, Foz do Iguassu-Brazil. 
rotating inertias value is pointed out through a parametric study.

\section{Modeling of hydraulic components}

By assuming uniform pressure and velocity distributions in the cross section and neglecting the convective terms, the onedimensional momentum and continuity balances for an elementary pipe filled with water of length $d x$, cross section $A$ and wave speed $a$, see Fig. 1, yields to the following set of hyperbolic partial differential equations [13]:

$$
\left\{\begin{array}{l}
\frac{\partial h}{\partial t}+\frac{a^{2}}{g A} \cdot \frac{\partial Q}{\partial x}=0 \\
\frac{\partial h}{\partial x}+\frac{1}{g A} \cdot \frac{\partial Q}{\partial t}+\frac{\lambda|Q|}{2 g D A^{2}} \cdot Q=0
\end{array}\right.
$$

The system (1) is solved using the Finite Difference Method with a $1^{\text {st }}$ order centered scheme discretization in space and a scheme of Lax for the discharge variable. This approach leads to a system of ordinary differential equations that can be represented as a T-shaped equivalent scheme [3], [8], [12] as presented in Fig. 2. The RLC parameters of this equivalent scheme are given by:

$$
R=\frac{\lambda \cdot|\bar{Q}| \cdot d x}{2 \cdot g \cdot D \cdot A^{2}} \quad L=\frac{d x}{g \cdot A} \quad C=\frac{g \cdot A \cdot d x}{a^{2}}
$$

Where $\lambda$ is the local loss coefficient. The hydraulic resistance $\mathrm{R}$, the hydraulic inductance $\mathrm{L}$, and the hydraulic capacitance $\mathrm{C}$ correspond respectively to energy losses, inertia and storage effects.

The model of a pipe of length $L$ is made of a series of $\mathrm{N}_{\mathrm{b}}$ elements based on the equivalent scheme of Fig. 2 . The system of equations relative to this model is set-up using Kirchoff laws. The model of the pipe, as well as the model of valve, surge tank, Francis turbine, etc, are implemented in the EPFL software SIMSEN, developed for the simulation of the dynamic behavior of hydroelectric power plants, [7], [11]. The time domain integration of the full system is achieved in SIMSEN by a Runge-Kutta $4^{\text {th }}$ order procedure.

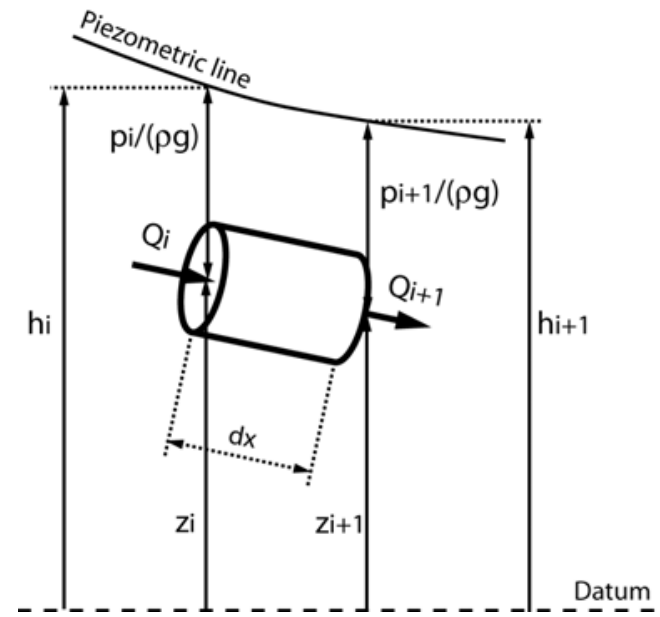

Fig. 1 Elementary hydraulic pipe of length dx.

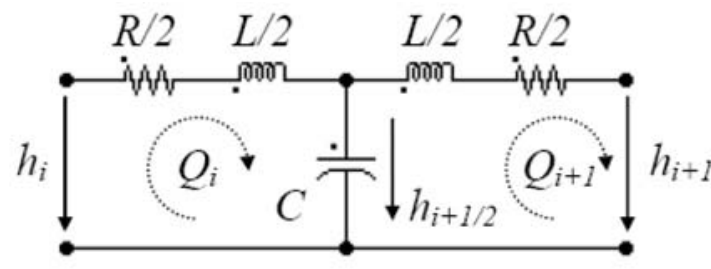

Fig. 2 Equivalent circuit of an elementary pipe of length $\mathrm{dx}$.

As presented in Table 1, the modeling approach based on equivalent schemes of hydraulic components is extended to all the standard hydraulic components such as valve, surge tanks, air vessels, cavitation development, Francis pump-turbines, Pelton turbines, Kaplan turbines, pump, etc, see [7]. 
Table 1 Modeling of hydraulic components with related equivalent schemes.

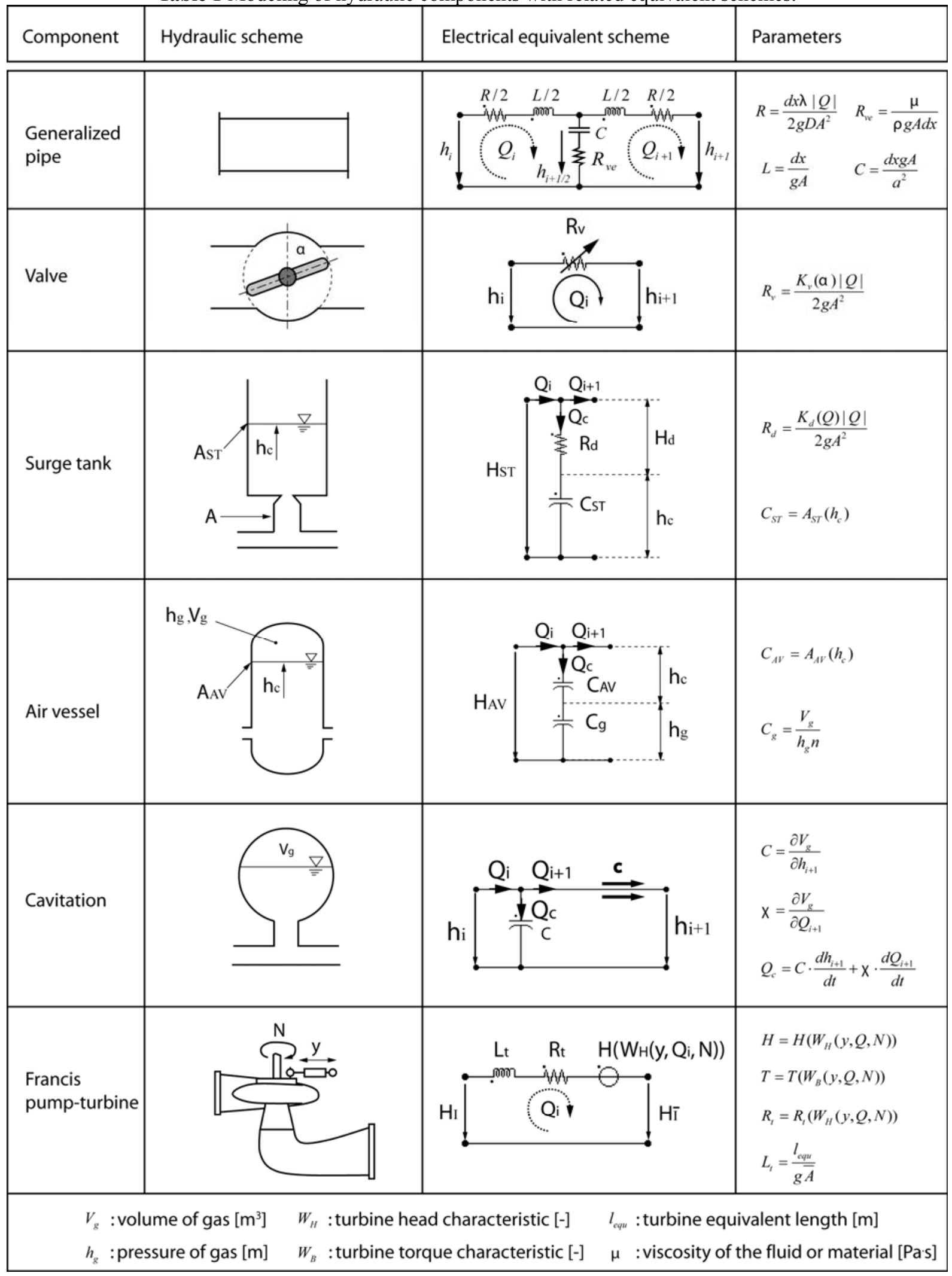




\section{Case study}

The test case presented in Fig. 3 comprises an upper reservoir, a 1100 meters long gallery, a surge tank with constant cross section $A_{u}=180 \mathrm{~m}^{2}$, a penstock of 975 meters feeding two Francis pump-turbines of $340 \mathrm{MW}$ connected to a downstream surge tank of $A_{d}=300 \mathrm{~m}^{2}$, and a 2500 meters long tailrace water tunnel. The rated parameters of the pump turbines are given in Table 2 .

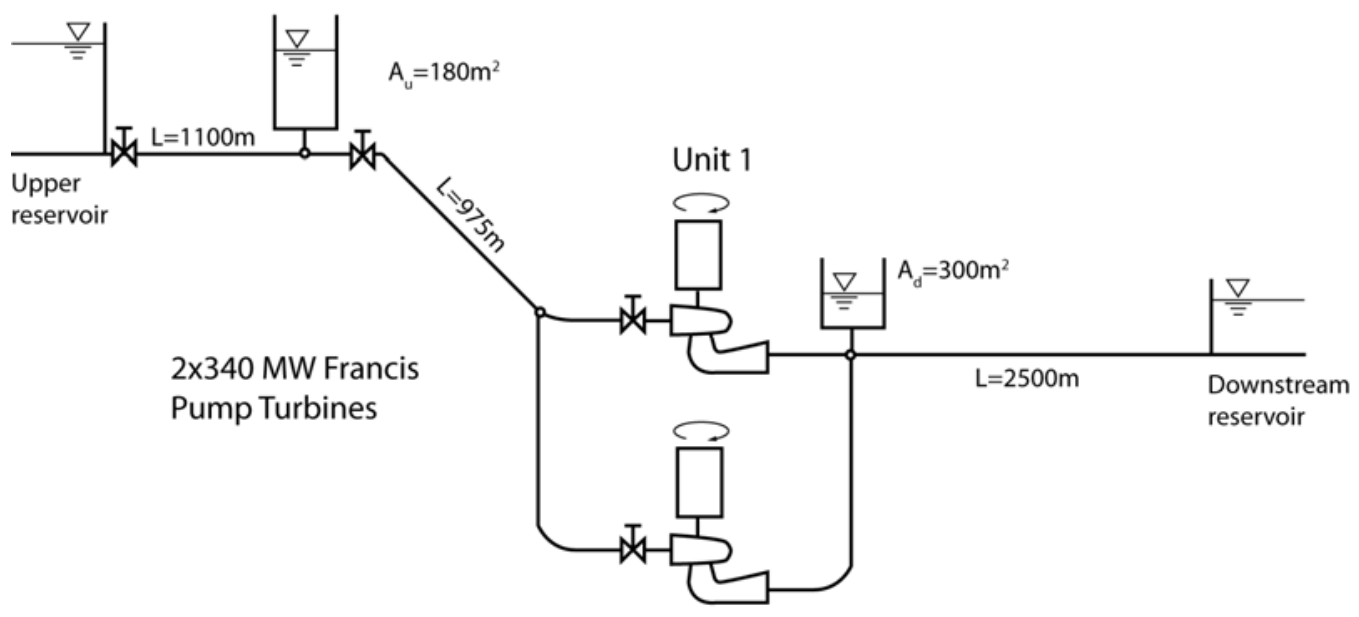

Unit 2

Fig. 3 Case study layout.

Table 2 Rated values of the pump-turbine of Fig. 3.

\begin{tabular}{|c|l|l|l|c|c|}
\hline $\mathbf{H}_{\mathbf{R}}[\mathbf{m}]$ & $\mathbf{Q}_{\mathbf{R}}\left[\mathbf{m}^{3} / \mathbf{s}\right]$ & $\mathbf{N}_{\mathbf{R}}[\mathbf{r p m}]$ & $\mathbf{P}_{\mathbf{R}}[\mathbf{M W}]$ & $\mathbf{N}[-]$ & $\mathbf{J}\left[\mathbf{K g}^{*} \mathbf{m}^{2}\right]$ \\
\hline \hline 440 & 86 & 428.6 & 340 & 0.26 & $1.5 \cdot 10^{6}$ \\
\hline
\end{tabular}

\section{Emergency shutdown in generating mode}

The transient behavior of the power plant of Fig. 3 is simulated with SIMSEN for the case of an emergency shutdown of the two units, operating close to the nominal operating point. A servomotor failure of Unit 1 is considered while the guide vanes of Unit 2 are closed linearly. The resulting transient behavior of Units 1 and 2 are presented respectively in Fig. 4 and Fig. 5.

\subsection{Short term transient: 0 to 100 seconds}

The Unit 2 is experiencing runaway that is reduced by the guide vane closure, while Unit 1, that have constant guide vane opening, is experiencing unstable operation at runaway due to the S-shape of the turbine characteristics inducing rotational speed, head, discharge and torque oscillation with a period of 15 seconds. Figure 4, right, shows the operating point trajectory in the planes $\mathrm{N}_{11}-\mathrm{Q}_{11}$ and $\mathrm{N}_{11}-\mathrm{T}_{11}$ of the Unit 1 evidencing the $\mathrm{S}$-shape of the turbine characteristic. Where $\mathrm{N}_{11}, \mathrm{Q}_{11}, \mathrm{~T}_{11}$ are respectively the speed, discharge and torque factors given by:

$$
N_{11}=\frac{N \cdot D_{r e f}}{\sqrt{H}} \quad ; \quad Q_{11}=\frac{Q}{D_{r e f}^{2} \cdot \sqrt{H}} \quad ; T_{11}=\frac{T}{D_{r e f}^{3} \cdot H}
$$
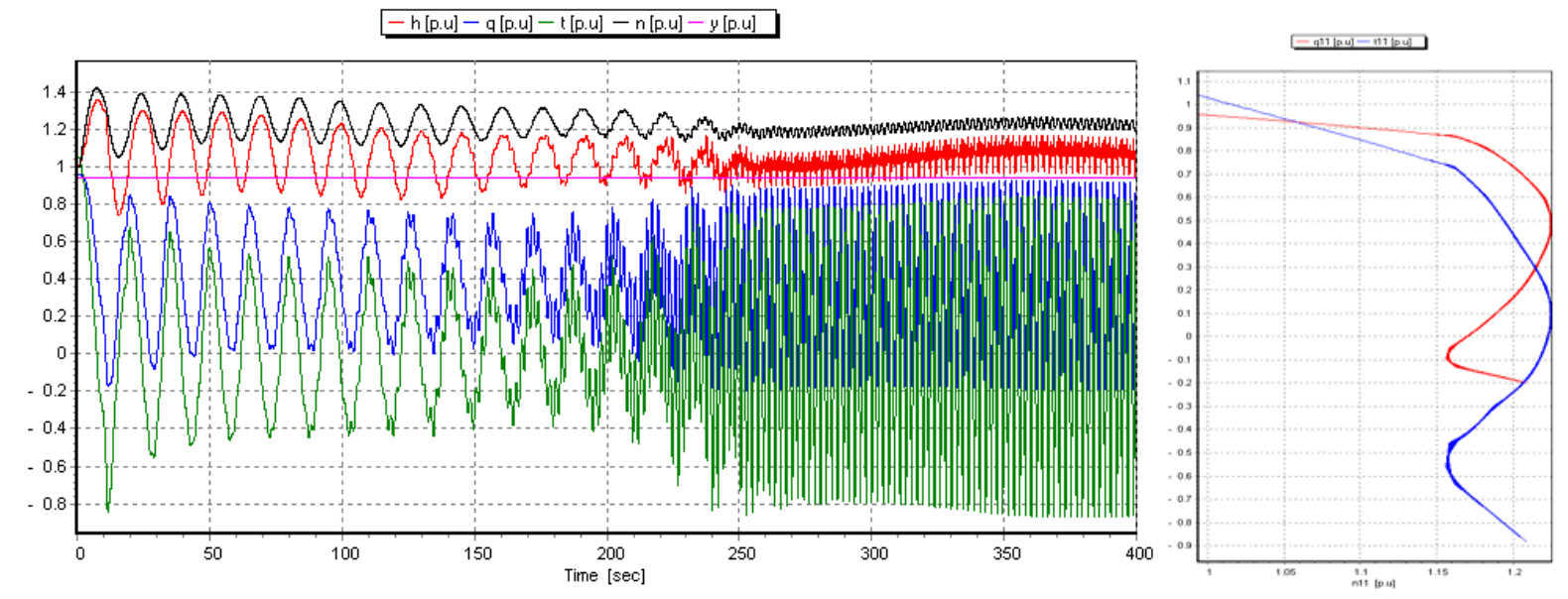

Fig. 4: Transient behavior of Unit 1 during emergency shutdown with servomotor failure (left) and related operating point trajectory in the plane $\mathrm{N}_{11}-\mathrm{Q}_{11}$ and $\mathrm{N}_{11}-\mathrm{T}_{11}$ (right). 


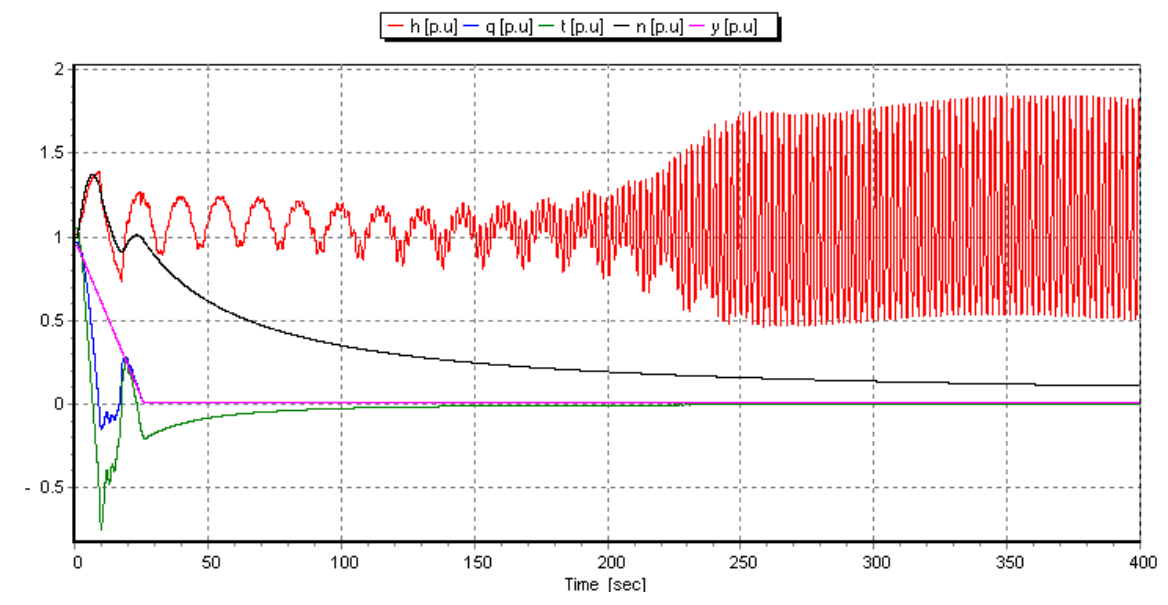

Fig. 5 Transient behavior of Unit 2 during emergency shutdown.

The runaway instability of Unit 1 corresponds to the so-called hydro-mechanical mode or rigid water column mode described by Martin [5], [6] which period depends on the total shaft line inertia $J_{t o t}$, including the rotor, the shafts and the turbine itself, the penstock water inertia and on the turbine's characteristic. One can express the angular momentum equation applied to the shaft line as follow:

$$
J_{t o t} \frac{d \omega}{d t}=\sum T
$$

From which the following mechanical time constant can be derived:

$$
\tau_{m}=\frac{J_{t o t} \cdot \omega_{R}}{T_{R}}
$$

The momentum equation applied to the penstock water can be expressed as follow:

$$
L_{p e n} \frac{d Q}{d t}=\Delta H
$$

With $L_{p e n}$, the hydraulic inductance of the penstock. From equation (6), one can deduce the hydraulic time constant of the penstock given by:

$$
\tau_{h}=\frac{l_{\text {pen }}}{g \cdot A_{\text {pen }}} \cdot \frac{Q_{R}}{H_{R}}
$$

And finally the water column mode period is given by:

$$
T_{R M}=\pi \cdot \sqrt{2 \cdot \frac{\tau_{m} \cdot \tau_{h}}{b 1}}
$$

Where $b 1$ is the slope of the turbine characteristic in the plane $\left(T / T_{R}\right) /\left(\omega / \omega_{R}\right)^{2}=f\left(\left(Q / Q_{R}\right) /\left(\omega / \omega_{R}\right)\right)$, for more details, please see [5].

For the test case, it gives, $\tau_{m}=8.88 \mathrm{~s}$ and $\tau_{h}=1.07 \mathrm{~s}$, with $\mathrm{b} 1=1.04$, leading to:

$$
T_{R W}=\pi \cdot \sqrt{2 \cdot \frac{\tau_{m} \cdot \tau_{h}}{b 1}}=13.4 \mathrm{~s}
$$

The theoretical period of the rigid water column mode agrees well with the period obtained by simulation of $T_{R W}=15 \mathrm{~s}$. The difference between the period obtained from the simulation and the period obtained from the linearized theory is due to the fact that the amplitude of the oscillations are above "small perturbation amplitudes", and consequently characteristics non-linearities influence the oscillation period.

\subsection{Long term transient: up to 100 seconds}

The emergency shutdown of the Units leads to a reduction of the discharge in the hydraulic system and consequently initiates upstream and downstream mass oscillations. The time evolution of the upstream and downstream water levels is presented in Fig. 6, pointing out the 2 different mass oscillations periods. 


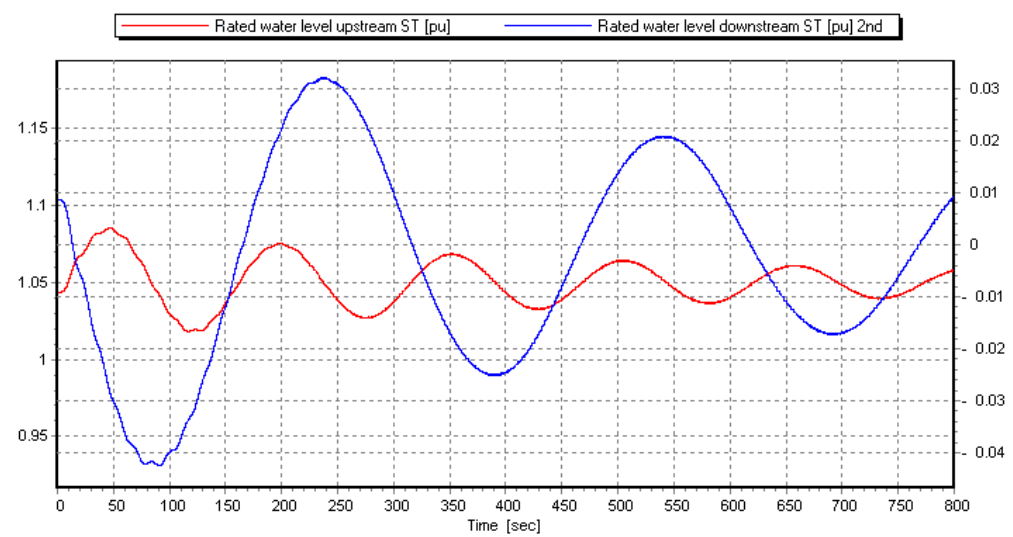

Fig. 6 Time evolution of the surge tanks rated water levels.

The most interesting point of the long term transient is the change of the behavior of the system instabilities that occurs between 100 seconds and 250 seconds. As presented in Fig. 4, it can be seen that the amplitudes of rotational speed and head of Unit 1 are decreasing while the amplitudes of the discharge and torque oscillations are strongly increasing, and the period of the oscillations is reduced to $\mathrm{T}_{\mathrm{EW}}=2.16 \mathrm{~s}$. In the same time, the head of the Unit 2 is oscillating at the same period and exhibits peakto-peak oscillation amplitudes of 1.3 times the rated head. Figure 7 presents the time evolution of the head along the penstock for different locations pointing out pressure fluctuations of peak-to-peak amplitudes of 1.7 times the rated head. The period of oscillation corresponds to the first natural frequency of the piping that can be calculated according to the total piping length comprised between the 2 surge tanks $L_{t o t}$ and the mean wave speed $\bar{a}$ and gives:

$$
f_{o}=\frac{a}{\lambda}=\frac{\bar{a}}{2 \cdot L_{t o t}}=\frac{1151}{2 \cdot 1243}=0.463 \mathrm{~Hz} \rightarrow T_{E W}=2.16 \mathrm{~s}
$$

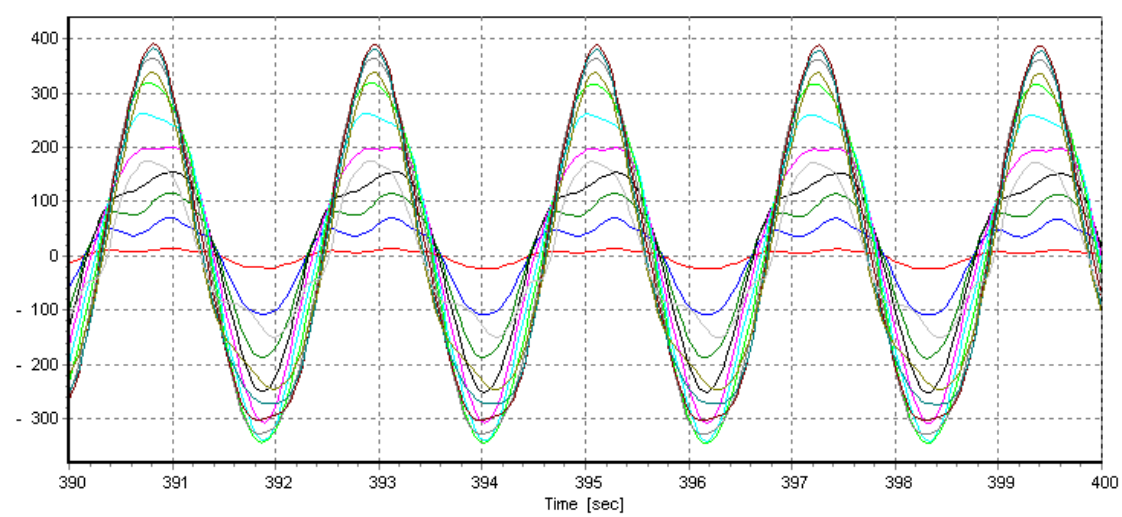

Fig. 7 Time evolution of the head along the pipe.

Consequently, the oscillation mode with a period of $2.16 \mathrm{~s}$ that arises after 250 seconds corresponds to the first natural frequency of the piping system which is excited by the turbine unstable behavior and dominates the rigid water column mode. This oscillation mode that involves the first piping natural frequency and the turbine is called elastic water column mode and was already observed on measurements by Dörfler et al. [1]. The difference in the denomination of the 2 modes lies to the fact that the rigid water column mode involves only inertias effects while the elastic column mode involves the compressibility effects of the piping system [4].

\section{Oscillation modes characterizations}

To characterize better the differences between the rigid and the elastic water column oscillation modes, the head along the piping system between the upstream and downstream surge tanks are represented during one period of oscillation for the rigid mode in Fig. 8 and for the elastic mode in Fig. 9.

From Fig. 8, one can notice that rotational speed and head are oscillating in phase and torque and discharge are oscillating also in phase, but with a shift of $90^{\circ}$ compared to head and rotational speed oscillations. The kinetic energy of the fluid is converted into angular kinetic energy of the mechanical inertias. The head amplitudes along the pipe appear to increase proportionally along the piping from the upstream surge tank until the turbine of Unit 1.

From Fig. 9, it can be seen that the amplitudes along the piping are drastically increased, as it corresponds to 1.7 times the rated head, and corresponds to the piping first natural mode shape. For the times $t_{o}$ and $t_{o}+T_{E W} / 2$, it can be noticed that the 
amplitudes are not equal to zero as it is for the rigid mode. This is due to the second natural mode shape of the piping system that is also exited but features lower amplitudes than the first natural mode shape.
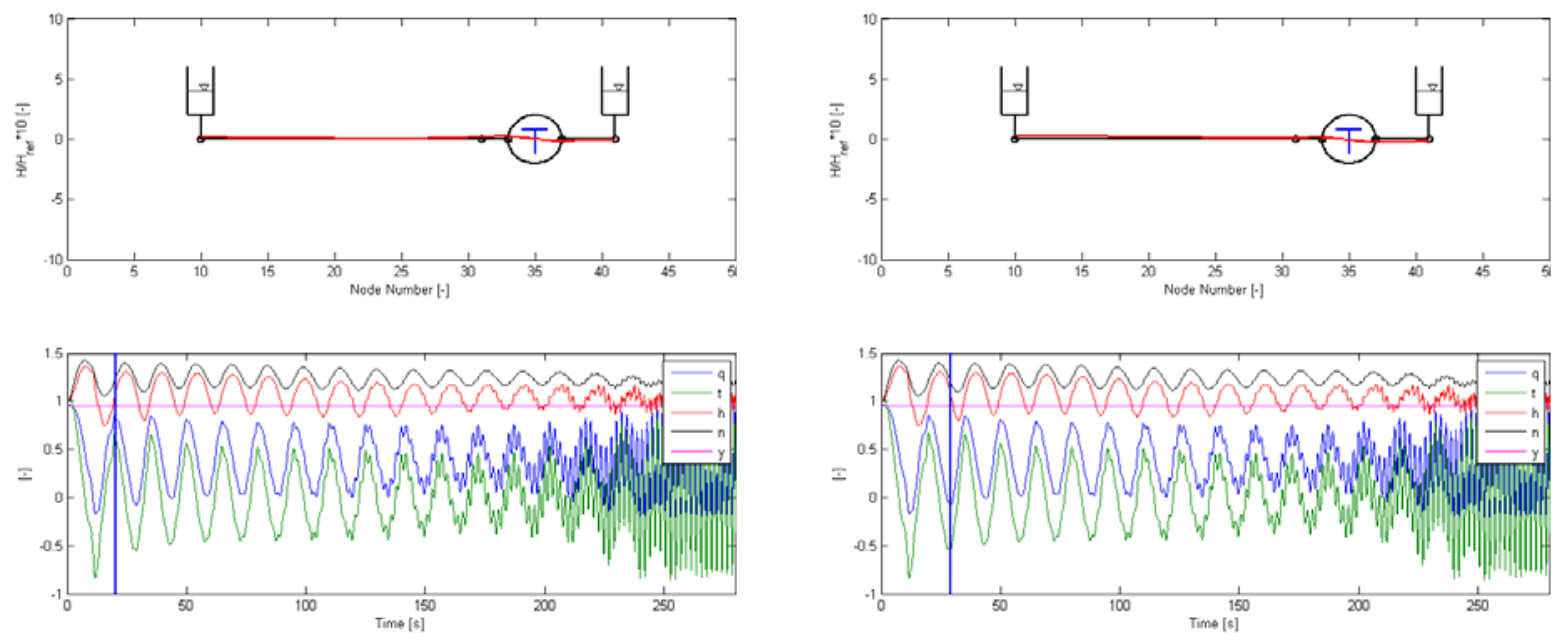

$$
t=t_{o}
$$

$$
t=t_{o}+T_{R W} / 2
$$
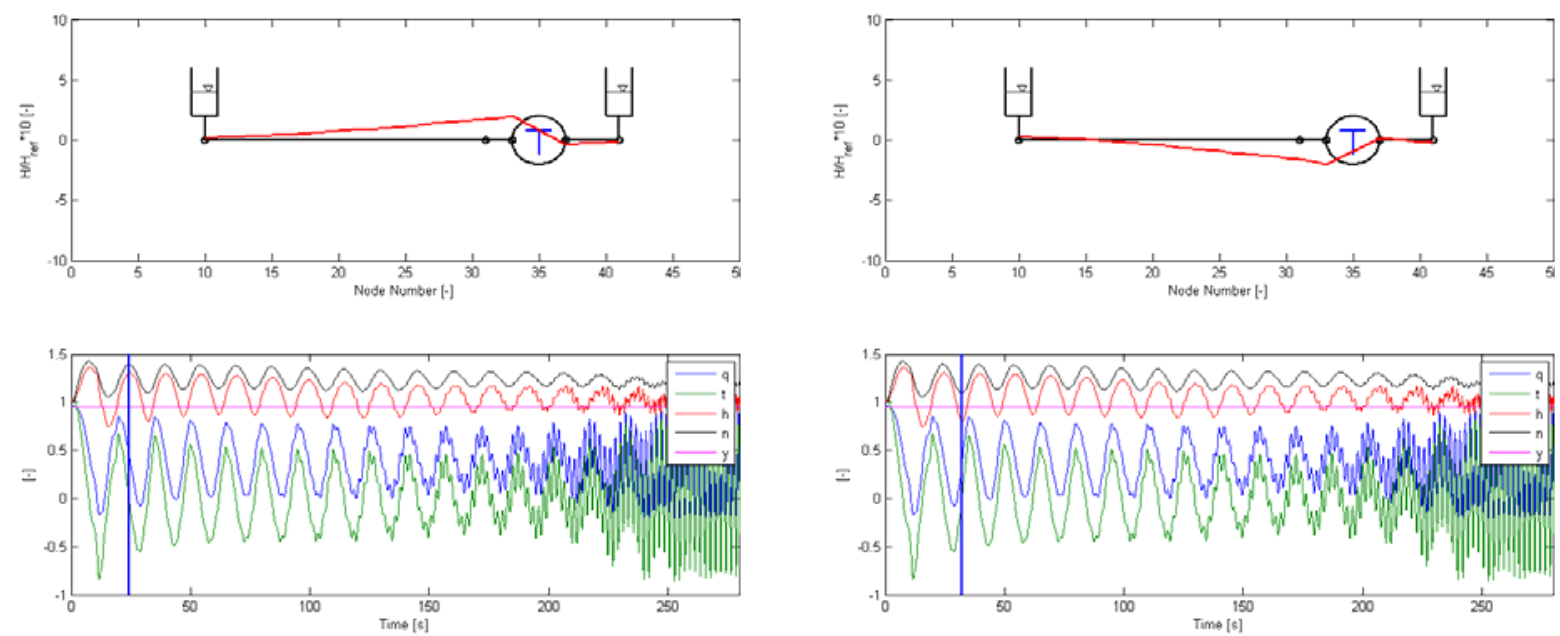

$$
t=t_{o}+T_{R W} / 4
$$

$$
t=t_{o}+3 \cdot T_{R W} / 4
$$

Fig. 8 Rigid water column mode.

It should be mentioned that for real emergency shutdown, the elastic water column mode would not have time to arise as there is closure of the protection valves for emergency shutdown. Typically, the main inlet valves are closing in $40-60 \mathrm{~s}$ and intake gate is closing in $120-180 \mathrm{~s}$. 

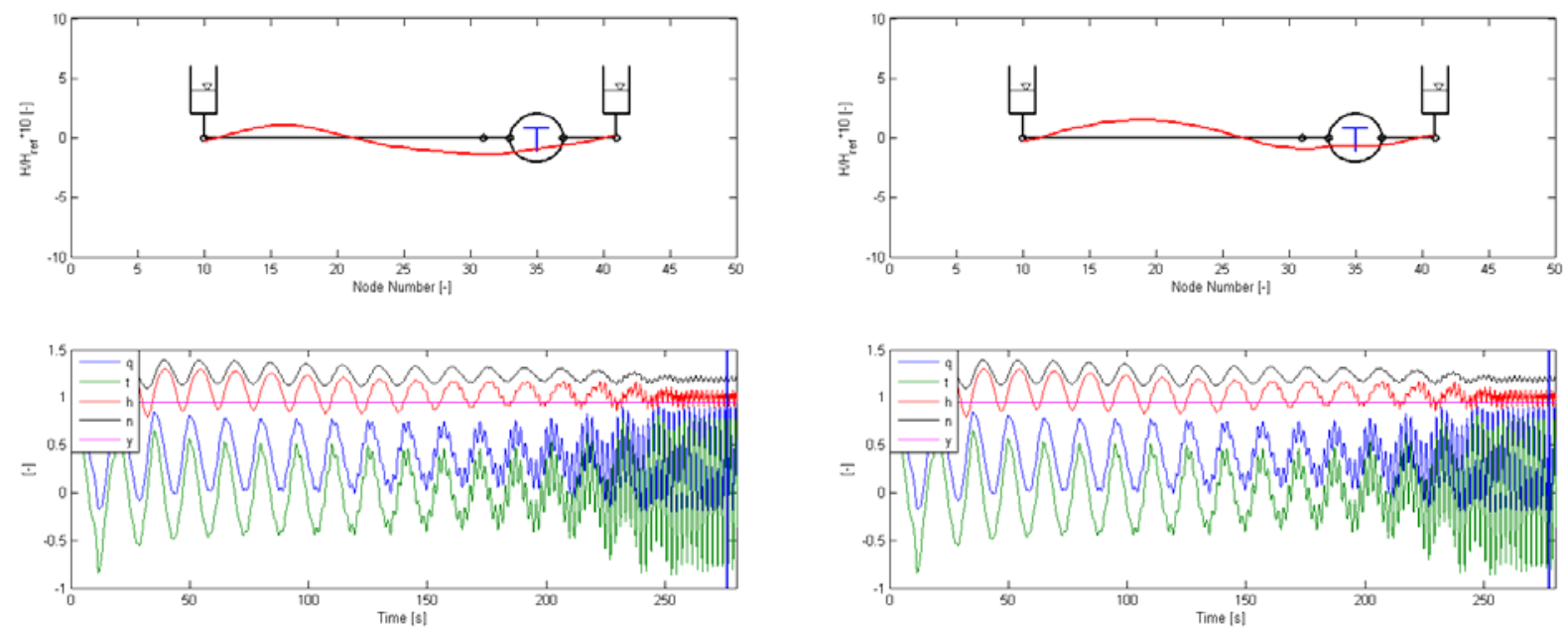

$t=t_{o}$

$$
t=t_{o}+T_{E W} / 2
$$
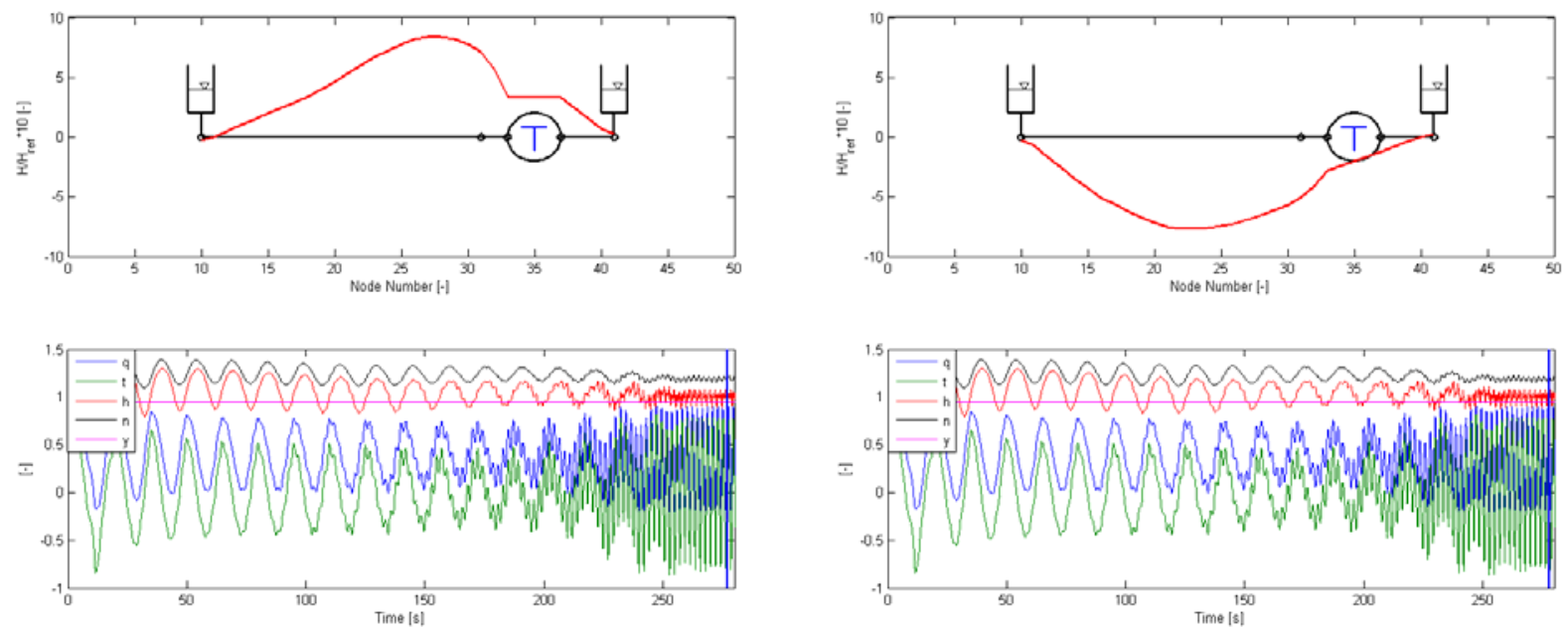

$$
t=t_{o}+T_{E W} / 4
$$

$$
t=t_{o}+3 \cdot T_{E W} / 4
$$

Fig. 9 Elastic water column mode.

\section{Parametric study}

As the rigid water column mode depends on the rotating inertias, a parametric study is undertaken with the rotating inertia as a parameter. The time evolution of the variables of the pump-turbine of Unit 1 is presented in Fig. 10 for 6 different values of the rotating inertias summarized in Table 3 . The inertia range extend from $\mathrm{J} / \mathrm{J}_{\text {ref }}=0.08$ to 1.66 . Table 3 also summarizes the rigid water column mode period $T_{R W}$ obtained from the different simulations.

Table 3 Values of the inertias of the simulations of Fig. 10 with $\mathrm{J}_{\mathrm{ref}}=1.525 \mathrm{e} 6 \mathrm{Kg} \mathrm{m}^{2}$.

\begin{tabular}{|c||c|c|c|c|c|c|}
\hline Case & a) & b) & c) & d) & e) & f) \\
\hline \hline $\mathbf{J}\left[\mathbf{K g} * \mathbf{m}^{2}\right]$ & $0.125 \mathrm{e} 6$ & $0.525 \mathrm{e} 6$ & $1.025 \mathrm{e} 6$ & $1.525 \mathrm{e} 6$ & $2.025 \mathrm{e} 6$ & $2.525 \mathrm{e} 6$ \\
\hline $\mathbf{J} / \mathbf{J}_{\mathbf{r e f}}[-]$ & 0.08 & 0.34 & 0.67 & 1 & 1.33 & 1.66 \\
\hline $\mathbf{T}_{\mathbf{R W}}[\mathbf{s}]$ & - & 8.6 & 12.3 & 15.0 & 17.0 & 19.0 \\
\hline $\mathbf{T}_{\mathbf{R W}} / \mathbf{T}_{\mathbf{E W}}[-]$ & - & 4.0 & 5.7 & 7.0 & 7.9 & 8.8 \\
\hline
\end{tabular}

Figure 10 shows that, as expected, the rigid water column mode period increases when the rotating inertia is increased. But the inertia value also influences the time at which the switch between the rigid and the elastic mode occurs: the higher is the inertia, the later the switch occurs. Moreover, for very low values of inertia $\left(\mathrm{J} / \mathrm{J}_{\text {ref }}=0.08\right)$ there is no rigid mode oscillation after unit shutdown and only the elastic mode is slowly excited by the turbine $\mathrm{S}$-shape characteristic. While for high values of inertia $\left(\mathrm{J} / \mathrm{J}_{\text {ref }}\right.$ $=1.66)$ there is no switch to the elastic mode and only the rigid mode is oscillating. The period of rigid mode rated by the elastic mode (always constant here) is represented as function of the rated inertia in Fig. 11. The time at which the switch between the modes occurs, is also represented. 


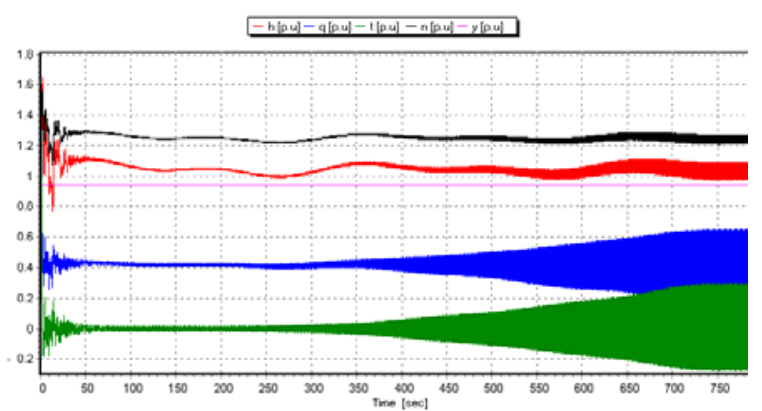

a)

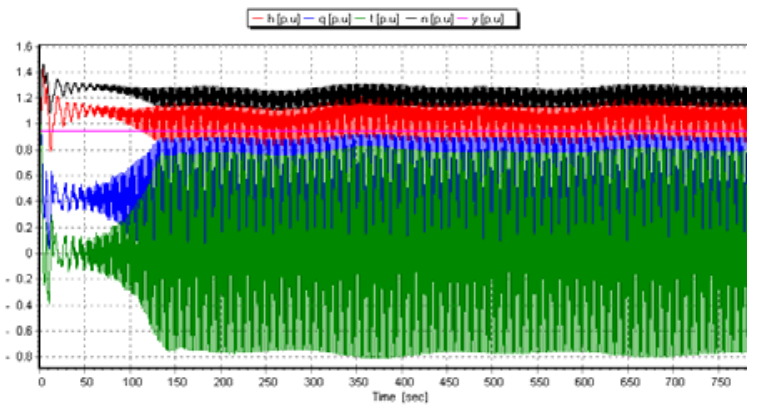

b)

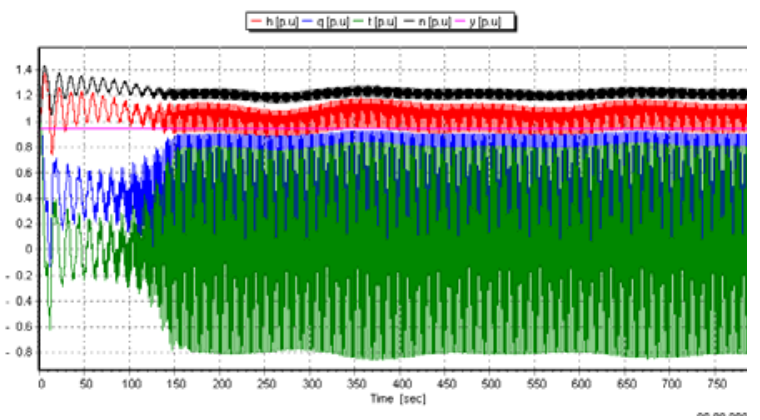

c)

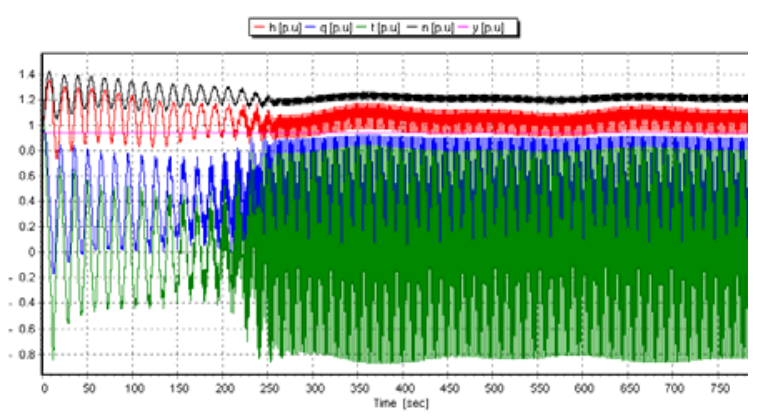

d)

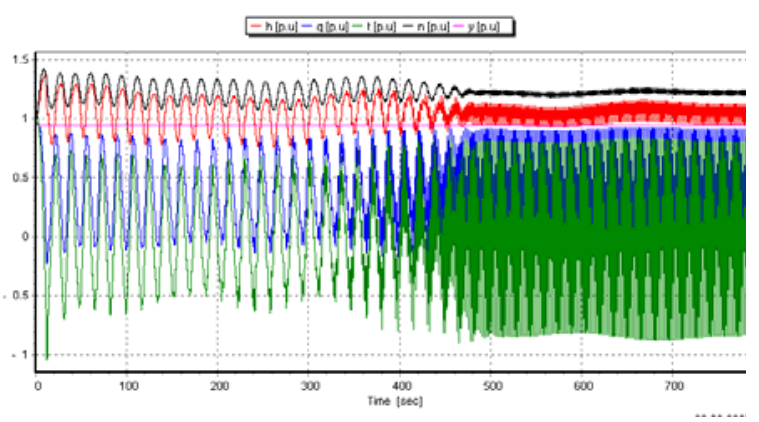

e)

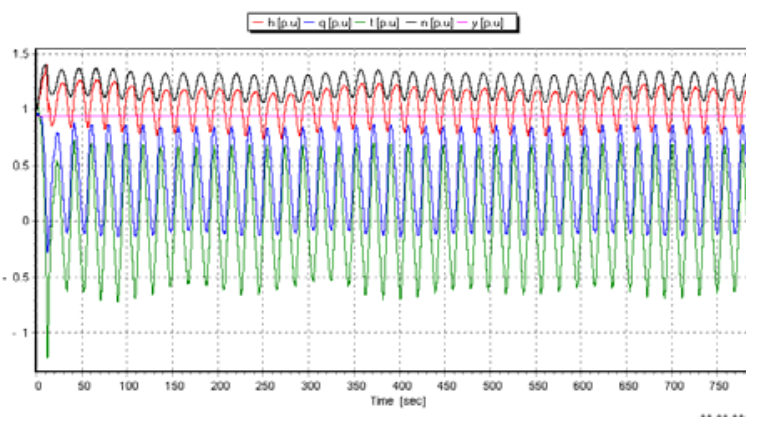

f)

Fig. 10 Time evolution of the pump-turbine 1 variables during the transient for 6 different values of rotating inertias given in Table 3 .

It can be noticed that, as expected, the period of the rigid mode is increasing with the rated inertia with a root square like evolution. The switch occurs only for a given range of rated inertia, between 0.34 and 1.33 corresponding to the rated frequencies $T_{R W} / T_{E W}$ ranging from 4 to 8 . When this ratio is too small, there is no rigid mode. If the rated period is too large, only the rigid mode is excited as there is too large difference between the two oscillation periods.

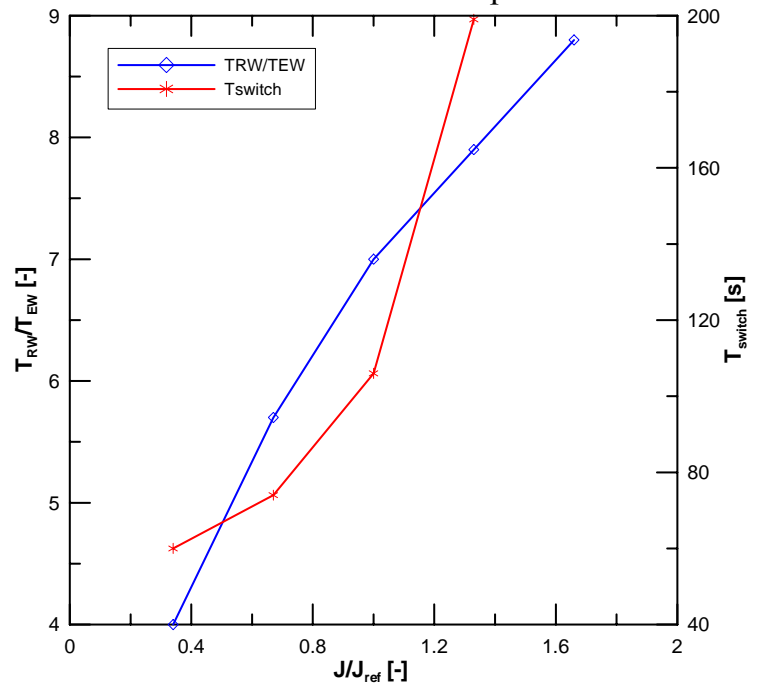

Fig. 11 Evolution of the rated period of the rigid mode and of the time until the switch as function of the rated inertias, see Table 3. 


\section{Conclusions}

This paper presents the simulation of unstable operation of a pump-turbine resulting from servomotor failure during emergency shutdown. It is pointed out that first the pump-turbine experiences rigid water column mode characterized by high period of oscillation of 15 seconds and that after 250 seconds there is switch from rigid column mode to elastic column mode oscillation. The elastic water column mode represents huge risk for the safety of the power plant if it occurs at high guide vane openings as the peak-to-peak pressure amplitudes can reach 1.7 times the rated head, possibly at penstock locations not even designed for the maximum design pressure. This emphasizes the importance of the protection redundancy with main inlet valve closure and intake gate closure after emergency shutdown. Consequently, it would be recommended to check the switch time between rigid and elastic mode from simulation to ensure that all the protection valves would have closed before the switch could happen and jeopardize the power plant safety.

\section{Nomenclature}

$\begin{array}{ll}A & \text { Pipe cross section }\left[\mathrm{m}^{2}\right] \\ A_{g} & \text { Gallery cross section }\left[\mathrm{m}^{2}\right] \\ A_{S T} & \text { Surge tank cross section }\left[\mathrm{m}^{2}\right] \\ D_{\text {ref }} & \text { Machine reference diameter }[\mathrm{m}] \\ H & \text { Net head }[\mathrm{m}] \\ Q & \text { Discharge }\left[\mathrm{m}^{3} / \mathrm{s}\right] \\ N & \text { Rotational speed }[\mathrm{rpm}] \\ P & \text { Power }[\mathrm{W}] \\ T & \text { Torque }[\mathrm{Nm}] \\ a & \text { Pipe wave speed }[\mathrm{m} / \mathrm{s}] \\ H & \text { Piezometric head } h=z+p /(\rho g)[\mathrm{m}] \\ g & \text { Gravity }\left[\mathrm{m} / \mathrm{s}^{2}\right]\end{array}$

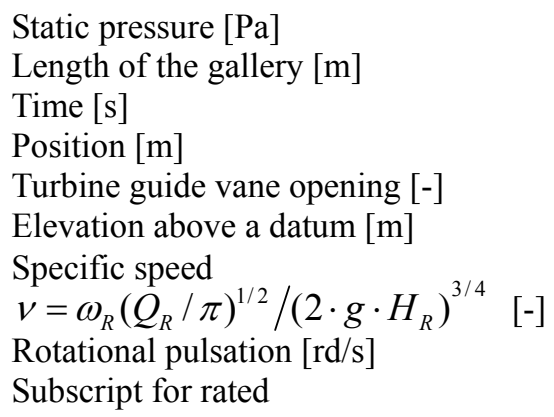

\section{References}

[1] Dörfler, P. K., Engineer, A. J., Pendse, R. N., Huvet, P., and Brahme, M. V., 1998, "Stable operation achieved on single-stage reversible pump-turbine showing instability at no-load". In Proceeding of the 19th IAHR Symposium on Hydraulic Machinery and Systems (Singapore), pp. 430-440.

[2] Huvet, P., 1992, "Steady oscillation between pump-turbine operating at partial flow and surge shaft", In Proc. 16th Symposium of the IAHR, Sao Paola, Brazil.

[3] Jaeger, R. C., 1977, "Fluid transients in hydro-electric engineering practice ".Glasgow: Blackie.

[4] Liu, X., Liu, C., 2007, "Eigenanalysis of Oscillatory Instability of a Hydropower Plant Incuding Water Conduit Dynamics", In IEEE Transactions on Power Systems, vol. 22, No. 2.

[5] Martin, C. S., 1986, "Stability of pump-turbines during transient operation”. In Proceedings of the 5th Int. Conf. on Pressure Surges (Hannover, Germany), pp. 61-71. paper C3.

[6] Martin, C. S., 2000, "Instability of pump-turbines with s-shaped characteristics". In Proceeding of the 20th IAHR Symposium on Hydraulic Machinery and Systems (Charlotte, USA).

[7] Nicolet, C., 2007, "Hydroacoustic modelling and numerical simulation of unsteady operation of hydroelectric systems", Thesis EPFL n 3751, (http://library.epfl.ch/theses/?nr=3751).

[8] Paynter, H. M., 1953, "Surge and water hammer problems". Transaction of ASCE, vol. 146, pp. 962-1009.

[9] Pejovic, S., Krsmanovic, L., Jemcov, R., Crnkovic, P., 1976, "Unstable operation of high-head reversible Pump-Turbines". In Proceeding of the 8th IAHR Symposium on Hydraulic Machinery and Systems, Leningrad, pp. 283-295.

[10] Taulan, J. P. 1983, "Pressure surges in hydroelectric installations - Peculiar effects of low specific speed turbine characteristics". Proc. 4th BHRA Int. Conf. on Pressure Surges, Bath, Paper H2, pp. 337-351.

[11] Sapin, A., 1995, "Logiciel modulaire pour la simulation et l'étude des systèmes d'entraînement et des réseaux électriques", Thesis EPFL n 1346, (http://library.epfl.ch/theses/?nr=1346).

[12] Souza, O.H., Jr.; Barbieri, N.; Santos, A.H.M., 1999, "Study of hydraulic transients in hydropower plants through simulation of nonlinear model of penstock and hydraulic turbine model," IEEE Transactions on Power Systems, vol. 14, issue 4, pp. 12691272.

[13] Wylie, E. B. \& Streeter, V.L., 1993, "Fluid transients in systems”. Prentice Hall, Englewood Cliffs, N.J. 